Check for updates

Cite this: RSC Adv., 2019, 9, 5142

Received 19th October 2018 Accepted 22nd January 2019

DOI: $10.1039 / c 8 r a 08685 k$

rsc.li/rsc-advances

\title{
Sulfonated carbon derived from the residue obtained after recovery of essential oil from the leaves of Cinnamomum longepaniculatum using Brønsted acid ionic liquid, and its use in the preparation of ellagic acid and gallic acid
}

\author{
Zaizhi Liu, (D) *ac Yanlong Qi, (DD ${ }^{\mathrm{b}}$ Mengling Gui, ${ }^{\mathrm{a}}$ Chunte Feng, ${ }^{\mathrm{c}}$ Xun Wang ${ }^{\mathrm{c}}$ \\ and Yang Lei*c
}

\begin{abstract}
A Brønsted acid ionic liquid, 3-methyl-1-(4-sulfonylbutyl) imidazolium hydrogensulfate $\left(\left[\mathrm{HO}_{3} \mathrm{~S}\left(\mathrm{CH}_{2}\right)_{4} \mathrm{mim}\right]\right.$ $\mathrm{HSO}_{4}$ ), was used for the first time for the preparation of a sulfonated carbon catalyst. The catalyst was prepared from the residue obtained after recovery of the essential oil from the leaves of Cinnamomum longepaniculatum. The sulfonated carbon catalyst with an amorphous structure attained high acidic efficiency at a sulfonation temperature of $200^{\circ} \mathrm{C}$ for $2 \mathrm{~h}$ of sulfonation time, and was characterised. SEM morphologies revealed that the carbon catalyst consisted of uniform carbon microspores. FTIR analysis, elemental analysis, and X-ray photoelectron spectroscopy revealed that the sulfonic acid group was successfully introduced on the surface of the sulfonated carbon catalyst. The result of TG analysis showed that the obtained sulfonated carbon catalyst has high thermal stability. Good acid and catalytic activity of the obtained sulfonated carbon catalyst were observed for the preparation of ellagic acid and gallic acid, which is comparable to those of diluted sulfuric acid and a sulfonated carbon catalyst that had been prepared with concentrated sulfuric acid. The excellent reusability of the sulfonated carbon catalyst was also confirmed by repeated experimental trials. In summary, the sulfonated catalyst derived from the residue obtained after recovery of essential oil from the leaves of C. longepaniculatum is an economic, eco-benign and promising substitute for traditional mineral acid catalysts for acidic catalysis in industrial applications.
\end{abstract}

\section{Introduction}

With diminishing fossil reserves and increasingly prominent environment problems, the comprehensive utilization of renewable resources and the production of platform chemicals have attracted great interest., ${ }^{1,2}$ As an important renewable resource for human survival and development, biomass accounts for a large proportion in nature and thus has a considerable potential to be used in the preparation of high value-added products through a series of varying bio-refinery procedures. $^{3}$ So far, the use of biomass as raw materials to produce fine chemical products (e.g., catalytic materials) is becoming increasingly attractive for both academic research and practical purposes owing to their multiple advantages. ${ }^{\mathbf{4}, 5}$ In

${ }^{a}$ College of Life Sciences, Jiangxi Normal University, Nanchang 330022, China. E-mail: zaizhiliu@hotmail.com

${ }^{b}$ Key Laboratory of Synthetic Rubber, Changchun Institute of Applied Chemistry, Chinese Academy of Sciences, Renmin Road, Changchun 5625, P. R. China

${ }^{c}$ Key Laboratory of Forest Plant Ecology, Ministry of Education, Northeast Forestry University, Harbin 150040, China.E-mail: yanglei@nefu.edu.cn light of "green chemistry", carbonaceous catalysts are versatile and have emerged as promising solid catalysts for chemical reactions. ${ }^{6,7}$ Cinnamomum longepaniculatum, belonging to the Lauraceae family, is rich in essential oil (main source of eucalyptol). For this reason, C. longepaniculatum has been widely cultivated and distributed in southwestern China as an economic crop, especially in the Yibin region (Sichuan province). ${ }^{\mathbf{8} 9}$ Each year, a large amount of residues after the extraction of essential oil are produced and discarded as byproducts; hence, a study focusing on the biorefining of this valuable plant biomass to aid the industrial chemistry is urgently needed to achieve an integrated exploitation of $C$. longepaniculatum as a source of natural products. Therefore, the residue obtained after the recovery of essential oil from the leaves of $C$. longepaniculatum would be an ideal raw material for post-processing of carbonaceous catalysts.

Ellagic acid and gallic acid are two important natural polyphenols with many bioactivities, which include antioxidant, ${ }^{\mathbf{1 0}}$ preservative effects, ${ }^{\mathbf{1 1}}$ antimycobacterial activity, ${ }^{\mathbf{1 2}}$ antiinflammatory and antitumor effects, ${ }^{13}$ and hence, they are widely used in food, pharmaceutical and cosmetic industries. Ellagic acid and gallic acid are present in the natural world in 
their free forms or as derivatives, and vary based on tree species; ${ }^{14}$ they are generally found as their derivatives (e.g., gallotannins and ellagitannins) in plant extracts. ${ }^{15}$ Conventionally, these two compounds are obtained mainly through several extraction methods involving heating or consumption of volatile organic solvents as well as acid hydrolysis of their derivatives with mineral acids as catalysts. ${ }^{16}$ Apart from the limitations of these methods, ${ }^{17}$ the use of homogeneous inorganic acid as catalysts in the hydrolysis procedures still has many disadvantages, such as the naturally corrosive threat on equipments, the high production of undesirable byproducts, sensitivity to water, tedious isolation process and the large input on the treatment of the acid-containing residues. ${ }^{18-21}$

Recently, sulfonated carbonaceous catalysts appeared as promising "green solid catalysts" for the application in acidic catalysis $^{22,23}$ because of their remarkable and stable solid acid characteristics, low cost, and easy availability through simple treatments. ${ }^{24-26}$ Nonetheless, a previous preparation process of sulfonated carbonaceous catalysts involves the post-processing of a carbon material for activation with concentrated sulfuric acid or other sulfonation compounds. ${ }^{27,28}$ Brønsted acid ionic liquids were first synthesized in 2002 by Cole et al. $^{29}$ and then researches conducted using them rapidly caught attention, mainly because Brønsted acid ionic liquids (especially functionalized with $-\mathrm{SO}_{3} \mathrm{H}$ group) not only exhibit strong Brønsted acidity, but also possess other remarkable characteristics just as other ionic liquids. ${ }^{30}$ To date, no attempt has been reported on the use of a Brønsted acid ionic liquid to substitute the traditional $-\mathrm{SO}_{3} \mathrm{H}$ group donors (e.g., sulfuric acid) to prepare sulfonated carbonaceous catalysts for acidic hydrolysis purposes.

In our previous study, a Brønsted acid ionic liquid 3-methyl1-(4-sulfonylbutyl) imidazolium hydrogensulfate $\left(\left[\mathrm{HO}_{3} \mathrm{~S}\left(\mathrm{CH}_{2}\right)_{4}\right.\right.$ mim] $\mathrm{HSO}_{4}$ ) was used as the dual extractant and catalyst for obtaining ellagic acid and gallic acid from crude extracts of Eucalyptus globulus leaves. However, the requirement for the purchase of $\left[\mathrm{HO}_{3} \mathrm{~S}\left(\mathrm{CH}_{2}\right)_{4} \mathrm{mim}\right] \mathrm{HSO}_{4}$ and recycling it from crude extracts in the industrial processes were the main concerns. In the present study, the residue obtained after recovery of the essential oil from the leaves of $C$. longepaniculatum was used as the raw material and $\left[\mathrm{HO}_{3} \mathrm{~S}\left(\mathrm{CH}_{2}\right)_{4} \mathrm{mim}\right] \mathrm{HSO}_{4}$ was first introduced in the preparation process of the sulfonated carbonaceous catalyst to replace the traditionally used concentrated sulfuric acid or other sulfonation compounds.

The synthesized sulfonated carbonaceous catalyst was successively characterized by X-ray Diffraction (XRD), Scanning Electron Microscopy (SEM), $\mathrm{N}_{2}$ adsorption-desorption isotherms, Fourier Transform Infrared Spectroscopy (FTIR), Thermogravimetric (TG) analysis, Elemental Analysis (EA), and X-ray Photoelectron Spectroscopy (XPS). The synthesized sulfonated carbonaceous catalyst was used to replace the liquid acidic catalysts in the preparation of ellagic acid and gallic acid by hydrolysis of their derivatives from E. globulus leaves. The performance of the prepared sulfonated carbonaceous catalyst was compared to that of the diluted sulfuric acid. Catalyst ability of the recycled sulfonated carbonaceous catalyst was also investigated to study its reusability.

\section{Materials and methods}

\subsection{Chemicals and materials}

Chromatographically pure (purity $\geq 95 \%$ ) ellagic acid (CAS no. 476-66-4) and gallic acid (CAS no. 149-91-7) were obtained from National Institute for the Control of Pharmaceutical and Biological Products (Beijing, China) as standards. $\left[\mathrm{HO}_{3} \mathrm{~S}\left(\mathrm{CH}_{2}\right)_{4}{ }^{-}\right.$ mim] $\mathrm{HSO}_{4}$ was provided from Chengjie Chemical Co. Ltd., (Shanghai, China) and used without further purification. Chromatographic grade methanol and acetic acid for the HPLC analysis, and spectral grade potassium bromide used for FTIR analysis were bought from Aladdin Reagent Co. Ltd., (Shanghai, China). Other chemicals used were of analytical grade and were purchased from Beijing Chemical Reagents Co. Ltd., (Beijing, China). A Milli-Q Water Purification system (Millipore, Waltham, MA, USA) was used for the depurated distilled water. Sample solutions were filtered using a $0.45 \mu \mathrm{m}$ nylon membrane before subjecting to HPLC analysis.

Dried C. longepaniculatum and E. globulus leaves were picked in autumn from Yibin city (Sichuan, China) and authorized by Professor Kailin Mo (Sichuan Academy of Forestry, China). All the samples were mashed and sieved into a proper size $(\leq 0.425$ $\mathrm{mm}$ ) and kept in a desiccator at ambient temperature before use. E. globulus crude extracts were extracted as described by Shin et $a l .{ }^{31}$ The residue obtained after recovery of the essential oil from the leaves of $C$. longepaniculatum was pre-extracted of essential oil and then dried prior to the usage as raw materials for the preparation of sulfonated carbonaceous catalyst.

\subsection{Preparation of the sulfonated carbon catalyst}

The starting materials (20 g) of the residue obtained after recovery of the essential oil from the leaves of Cinnamomum longepaniculatum was initially carbonized with a heating speed of $30{ }^{\circ} \mathrm{C} \mathrm{min}$ m $^{-1}$ to $400{ }^{\circ} \mathrm{C}$ for $6 \mathrm{~h}$ under $\mathrm{N}_{2}$ flow to prepare a black solid, namely, carbonaceous materials. The above black powder $(2 \mathrm{~g})$ was separately mixed with pure $\left[\mathrm{HO}_{3} \mathrm{~S}\left(\mathrm{CH}_{2}\right)_{4} \mathrm{mim}\right] \mathrm{HSO}_{4}$ or concentrated sulfuric acid and subsequently heated under a set temperature for a pre-set sulfonation time to introduce the $-\mathrm{SO}_{3} \mathrm{H}$ group onto the carbonaceous materials' surface, and then cooled to atmospheric temperature. The sulfonation reaction was performed in a Teflon autoclave under pure $\mathrm{N}_{2}$ atmosphere and a hot air oven was used for heating to the preset sulfonation temperature. ${ }^{32}$ The reaction mixtures were then washed three times by adding $100 \mathrm{~mL}$ of hot distilled water (80 ${ }^{\circ} \mathrm{C}$ ), followed by the separation of black precipitates from the suspension by centrifugation. The washing processes were repeated until no impurities (e.g., sulfate ions) were determined in the washing water. The black solid was then placed in an oven and dried for $12 \mathrm{~h}$ at $80{ }^{\circ} \mathrm{C}$. The parameters of $\left[\mathrm{HO}_{3}\right.$ $\left.\mathrm{S}\left(\mathrm{CH}_{2}\right)_{4} \mathrm{mim}\right] \mathrm{HSO}_{4}$ amount, sulfonation temperature and time were investigated by single factor experiments during the preparation process of the sulfonated carbon catalyst.

\subsection{Catalytic tests}

The heat reflux method was carried out to test the catalytic capacity of the prepared sulfonated carbon catalysts using 
$\left[\mathrm{HO}_{3} \mathrm{~S}\left(\mathrm{CH}_{2}\right)_{4} \mathrm{mim}\right] \mathrm{HSO}_{4}$ or concentrated sulfuric acid and was compared to that of the diluted sulfuric acid for the hydrolysis of E. globulus crude extracts. Briefly, E. globulus leaves crude extracts solution was mixed with $5 \%$ of the prepared sulfonated carbon catalyst or the same acidity $(\mathrm{pH} 1.0)$ of diluted sulfuric acid to make a comparison and then treated for $4 \mathrm{~h}$ by an electric jacket at $1000 \mathrm{~W}$. After the treatment was completed, the solutions $(1 \mathrm{~mL})$ were filtered and then analyzed by HPLC analysis to measure the yields of the two target compounds; their yields were expressed as milligram of ellagic acid and gallic acid per gram E. globulus leaf powder. The experiments were carried out in triplicate, and the yields of the two target compounds were denoted as mean $\pm \mathrm{SD}$. The HPLC analysis program for the analysis of the obtained ellagic acid and gallic acid was based on our previous study. ${ }^{14}$ The remaining reaction mixtures were isolated by centrifugation, and the precipitates were recovered through ethanol washing and drying at $80{ }^{\circ} \mathrm{C}$ before using for the reusability test.

\subsection{Physical measurement}

XRD patterns of the carbonaceous materials before and after the sulfonation treatment were collected using an X-ray diffractometer with $\mathrm{Cu}-\mathrm{K} \alpha$ radiation $(30 \mathrm{~mA}, 40 \mathrm{kV})$ at a step length of $0.02^{\circ}$ over $2 \theta$ with a range from $5^{\circ}$ to $60^{\circ}$. SEM morphologies were recorded on an S-3400N scanning electron microscope (HITACHI, Japan). The sulfonated carbon catalysts prepared using concentrated sulfuric acid and $\left[\mathrm{HO}_{3} \mathrm{~S}\left(\mathrm{CH}_{2}\right)_{4}\right.$ mim] $\mathrm{HSO}_{4}$ were characterized by $\mathrm{N}_{2}$ adsorption-desorption isotherms using a Quantachrome Autosorb-iQ apparatus. The samples were prepared as $\mathrm{KBr}$ discs and the spectra were recorded using a Magna-IR 560 (Nicolet, USA), and the wavenumber range of the IR spectrometer was $4000-500 \mathrm{~cm}^{-1}$. TG analyses of carbonaceous materials and sulfonated carbon catalysts were performed on a STA 409PC thermo-gravimetrical analyzer (NETZSCH, Germany) and the heating program was conducted with the temperature increasing from $26^{\circ} \mathrm{C}$ to $750{ }^{\circ} \mathrm{C}$ at a rate of $20^{\circ} \mathrm{C} \mathrm{min}{ }^{-1}$ with the total run time of $36.20 \mathrm{~min}$. EA of the carbon materials before and after the sulfonation treatment was studied using a VARIO ELcube Elemental Analyzer (Elementar, Germany) with the oxygen percentage calculated by content difference. XPS analysis was performed by an Axis THERMO X-ray photoelectron spectroscopy (Thermo Electron American) to detect the surface structures of the carbonaceous materials and sulfonated carbon materials. The acidic site contents of the sulfonated carbon catalysts that were prepared by $\left[\mathrm{HO}_{3} \mathrm{~S}\left(\mathrm{CH}_{2}\right)_{4} \mathrm{mim}\right] \mathrm{HSO}_{4}$ was determined by acid-base titration method as described by $\mathrm{Xu}$ et al. ${ }^{33}$

\section{Results and discussion}

\subsection{Single factor experiment}

3.1.1. Effect of $\left[\mathrm{HO}_{3} \mathrm{~S}\left(\mathrm{CH}_{2}\right)_{4} \mathrm{mim}\right] \mathrm{HSO}_{4}$ amount. Fig. 1a shows the influence of the amount of $\left[\mathrm{HO}_{3} \mathrm{~S}\left(\mathrm{CH}_{2}\right)_{4} \mathrm{mim}\right] \mathrm{HSO}_{4}$ on the preparation of sulfonated carbon catalyst with the sulfonation temperature and sulfonation time fixed at $200{ }^{\circ} \mathrm{C}$ and $2 \mathrm{~h}$. The yields of ellagic acid and gallic acid were
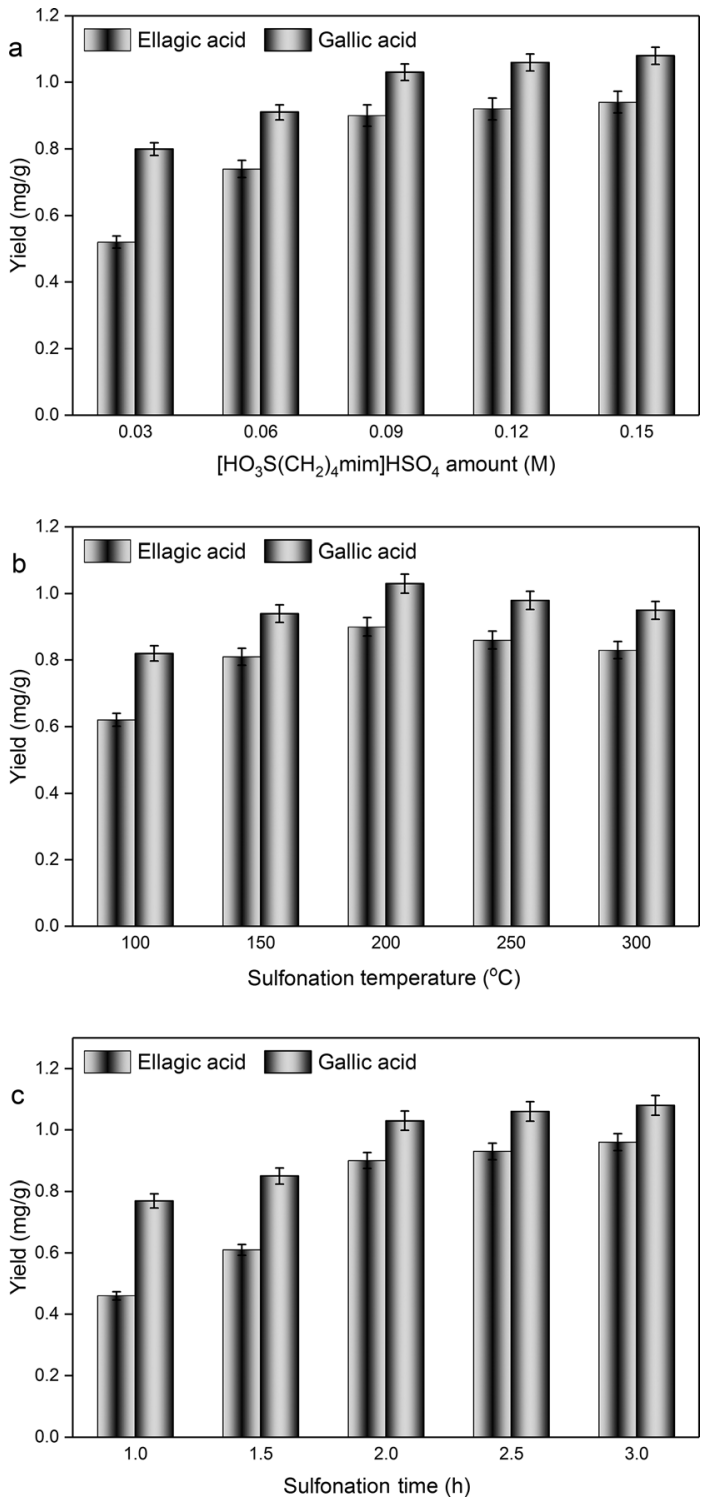

Fig. 1 Single factor experiments. Effect of $\left[\mathrm{HO}_{3} \mathrm{~S}\left(\mathrm{CH}_{2}\right)_{4}\right.$ mim $] \mathrm{HSO}_{4}$ amount (a), sulfonation temperature (b), and sulfonation time (c) on the preparation of sulfonated carbon catalyst from C. longepaniculatum leaves for the preparation of ellagic acid and gallic acid.

significantly low for a small amount of $\left[\mathrm{HO}_{3} \mathrm{~S}\left(\mathrm{CH}_{2}\right)_{4} \mathrm{mim}\right] \mathrm{HSO}_{4}$, and increased with the increase in the amount to $0.09 \mathrm{M}$; when the amount exceeded $0.09 \mathrm{M}$, there was only a slight increase in the yield of the acids. When a small amount of $\left[\mathrm{HO}_{3} \mathrm{~S}\left(\mathrm{CH}_{2}\right)_{4}{ }^{-}\right.$ $\mathrm{mim}] \mathrm{HSO}_{4}$ was used, the carbonaceous material surface could not be adequately occupied by $-\mathrm{SO}_{3} \mathrm{H}$ groups, hence there is an insufficient number of active acid sites and the catalytic capacity is low. Nonetheless, a large amount of $\left[\mathrm{HO}_{3} \mathrm{~S}\left(\mathrm{CH}_{2}\right)_{4}{ }^{-}\right.$ mim] $\mathrm{HSO}_{4}$ would make no distinct change in increasing the yields of the target compounds if the carbonaceous material surface occupied by the $-\mathrm{SO}_{3} \mathrm{H}$ group approaches a saturated state, based on the literature. ${ }^{34}$ Therefore, $0.09 \mathrm{M}$ as the concentration for $\left[\mathrm{HO}_{3} \mathrm{~S}\left(\mathrm{CH}_{2}\right)_{4} \mathrm{mim}\right] \mathrm{HSO}_{4}$ was chosen for the preparation of the sulfonated carbon catalyst. 
3.1.2. Effect of sulfonation temperature. Fig. 1b displays the effect of the sulfonation temperature on the sulfonated carbon catalyst preparation process with fixed $\left[\mathrm{HO}_{3} \mathrm{~S}\left(\mathrm{CH}_{2}\right)_{4} \mathrm{mim}\right]$ $\mathrm{HSO}_{4}$ amount and sulfonation time of $0.09 \mathrm{M}$ and $2 \mathrm{~h}$, respectively. With an increase in the sulfonation temperature from $100{ }^{\circ} \mathrm{C}$ to $200{ }^{\circ} \mathrm{C}$, the yields of the two compounds increased from $0.62 \pm 0.02 \mathrm{mg} \mathrm{g}^{-1}$ to $0.90 \pm 0.03 \mathrm{mg} \mathrm{g}^{-1}$ for ellagic acid and from $0.82 \pm 0.02 \mathrm{mg} \mathrm{g}^{-1}$ to $1.03 \pm 0.02 \mathrm{mg} \mathrm{g}^{-1}$ for gallic acid. No further improvement in the ellagic acid and gallic acid yields were observed with an increase in the sulfonation temperature from $200{ }^{\circ} \mathrm{C}$ to $300^{\circ} \mathrm{C}$. This phenomenon is likely because the low sulfonation temperature does not facilitate the formation of chemical linkages between the $-\mathrm{SO}_{3} \mathrm{H}$ group and the carbonaceous materials, and, therefore, the number of acidic sites on the prepared sulfonated carbon catalyst was inadequate. Likewise, the catalytic capacity of the prepared sulfonated carbon catalyst was low as expected with a shortage of acidic sites. An increase in the sulfonation temperature could accelerate the mass transfer between the $-\mathrm{SO}_{3} \mathrm{H}$ group donor and the carbonaceous materials to strengthen the sulfonation process, ${ }^{35}$ but the excessively high sulfonation temperature may trigger the degradation of some components and negatively affect the acid density. ${ }^{36}$ Herein, a sulfonation temperature of $200{ }^{\circ} \mathrm{C}$ was chosen for the subsequent preparation procedure.

3.1.3. Effect of sulfonation time. A suitable sulfonation time is essential for the linkage of $-\mathrm{SO}_{3} \mathrm{H}$ groups and carbon materials during the sulfonated carbon catalyst preparation process. Nevertheless, $\left[\mathrm{HO}_{3} \mathrm{~S}\left(\mathrm{CH}_{2}\right)_{4} \mathrm{mim}\right] \mathrm{HSO}_{4}$ is continuously consumed during the sulfonation reaction and reaction equilibrium is gradually reached. As presented in Fig. 1c, prolonging the sulfonation time from $1 \mathrm{~h}$ to $2 \mathrm{~h}$ resulted in a gradual increase in the yields of ellagic acid and gallic acid. The longer sulfonation time did not result in the enhancement of the corresponding yields, which basically displayed a plateau up to $3 \mathrm{~h}$ of sulfonation time. This similar phenomenon was also observed by Niu et al. ${ }^{36}$ during the preparation of sulfonated activated carbon from bamboo. Based on these results, a sulfonation time of $2 \mathrm{~h}$ was used for the preparation of $C$. longepaniculatum sulfonated carbon catalyst.

Based on these results, the parameters for the preparation of C. longepaniculatum sulfonated carbon catalyst using $\left[\mathrm{HO}_{3}\right.$ $\left.\mathrm{S}\left(\mathrm{CH}_{2}\right)_{4} \mathrm{mim}\right] \mathrm{HSO}_{4}$ were as follows: $0.09 \mathrm{M}$ of $\left[\mathrm{HO}_{3} \mathrm{~S}\left(\mathrm{CH}_{2}\right)_{4} \mathrm{mim}\right]$ $\mathrm{HSO}_{4}, 200{ }^{\circ} \mathrm{C}$ as the sulfonation temperature, and $2 \mathrm{~h}$ as the sulfonation time. Under these conditions, the prepared sulfonated carbon catalyst possessed high acidic capacity with yields of $0.90 \pm 0.03 \mathrm{mg} \mathrm{g}^{-1}$ for ellagic acid and $1.03 \pm 0.02 \mathrm{mg}$ $\mathrm{g}^{-1}$ for gallic acid, which is considerably higher than those prepared with diluted sulfuric acid $\left(0.98 \pm 0.03 \mathrm{mg} \mathrm{g}^{-1}\right.$ for ellagic acid and $1.16 \pm 0.04 \mathrm{mg} \mathrm{g}^{-1}$ for gallic acid) and concentrated sulfuric acid $\left(0.94 \pm 0.02 \mathrm{mg} \mathrm{g}^{-1}\right.$ for ellagic acid and $1.10 \pm 0.03 \mathrm{mg} \mathrm{g}^{-1}$ for gallic acid).

\subsection{Structural characterization of the obtained C. longepaniculatum sulfonated carbon catalysts}

3.2.1. XRD results. The XRD pattern reflects that the structure is an intermediate between graphite and amorphous carbon, i.e., it has a disorderly layer or random layer lattice structure. ${ }^{37}$ Fig. 2 presents the XRD patterns of the carbonaceous materials before (a) and after sulfonation by $\left[\mathrm{HO}_{3}\right.$ $\left.\mathrm{S}\left(\mathrm{CH}_{2}\right)_{4} \mathrm{mim}\right] \mathrm{HSO}_{4}$ (b). The strong and broad diffraction peaks of two samples observed in the figure at $2 \theta$ from $15^{\circ}$ to $30^{\circ}$ suggest an amorphous carbon structure that consists of the random orientation of aromatic sheets with a $C(002)$ plane, where the broad peak reflects a strong disordered degree and the relatively narrow peak indicates the weakened random carbon structure after sulfonation treatment. ${ }^{37}$

3.2.2. SEM morphologies. The SEM morphologies of carbonaceous materials (a), the carbon catalysts sulfonated by concentrated sulfuric acid (b) and $\left[\mathrm{HO}_{3} \mathrm{~S}\left(\mathrm{CH}_{2}\right)_{4} \mathrm{mim}\right] \mathrm{HSO}_{4}$ (c) are presented in Fig. 3. The raw carbonaceous materials without further sulfonation (a) consisted mainly of uniform carbon microspores. After chemical treatment by concentrated sulfuric acid (b) and by $\left[\mathrm{HO}_{3} \mathrm{~S}\left(\mathrm{CH}_{2}\right)_{4}\right.$ mim] $\mathrm{HSO}_{4}$ (c), the raw carbonaceous materials were broken into aggregates to a certain extent with relatively less microspores, especially in the sulfonated carbon catalyst using concentrated sulfuric acid.

3.2.3. The $\mathrm{N}_{2}$ adsorption/desorption results of the obtained materials. Fig. 4 shows the nitrogen adsorption/ desorption isotherms of the carbon catalysts sulfonated by concentrated sulfuric acid (a) and $\left[\mathrm{HO}_{3} \mathrm{~S}\left(\mathrm{CH}_{2}\right)_{4} \mathrm{mim}\right] \mathrm{HSO}_{4}$ (b). Both the obtained sulfonated carbon catalysts exhibit an isotherm of type III, which indicates that they are a typical of multilayer untypical porous materials. Meanwhile, the presence of hysteresis loops in the two prepared sulfonated carbon catalysts indicates the presence of mesopores. Mesopore size distribution of the carbon catalysts that were sulfonated by concentrated sulfuric acid and $\left[\mathrm{HO}_{3} \mathrm{~S}\left(\mathrm{CH}_{2}\right)_{4} \mathrm{mim}\right] \mathrm{HSO}_{4}$ are shown in Fig. 4c and d, from which it can be concluded that the pore size distribution is wide and micropores and mesopores under $15 \mathrm{~nm}$ are present in both the obtained sulfonated carbon catalysts. In addition, the specific surface area of the carbon catalysts sulfonated by concentrated sulfuric acid and $\left[\mathrm{HO}_{3} \mathrm{~S}\left(\mathrm{CH}_{2}\right)_{4} \mathrm{mim}\right] \mathrm{HSO}_{4}$ computed using the BET equation were 5.62 and $24.92 \mathrm{~m}^{2} \mathrm{~g}^{-1}$, respectively.

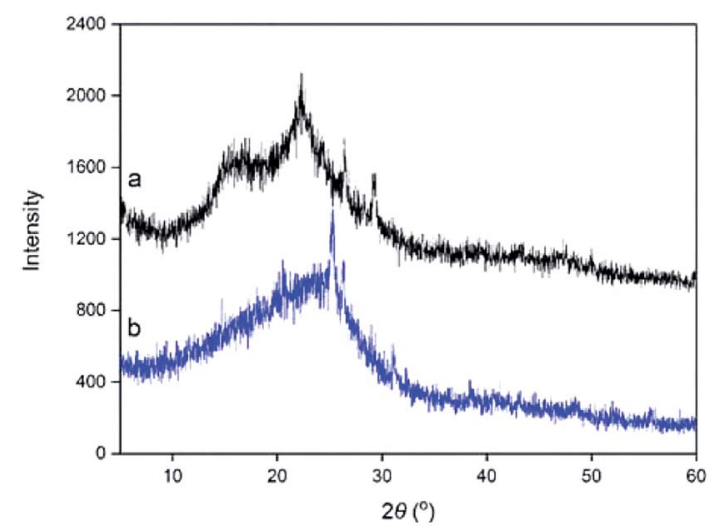

Fig. 2 XRD patterns of the carbonaceous materials from the residue obtained after recovery of essential oil from the leaves of $C$. longepaniculatum before (a) and after sulfonation by $\left[\mathrm{HO}_{3} \mathrm{~S}\left(\mathrm{CH}_{2}\right)_{4}\right.$ mim] $\mathrm{HSO}_{4}$ (b). 

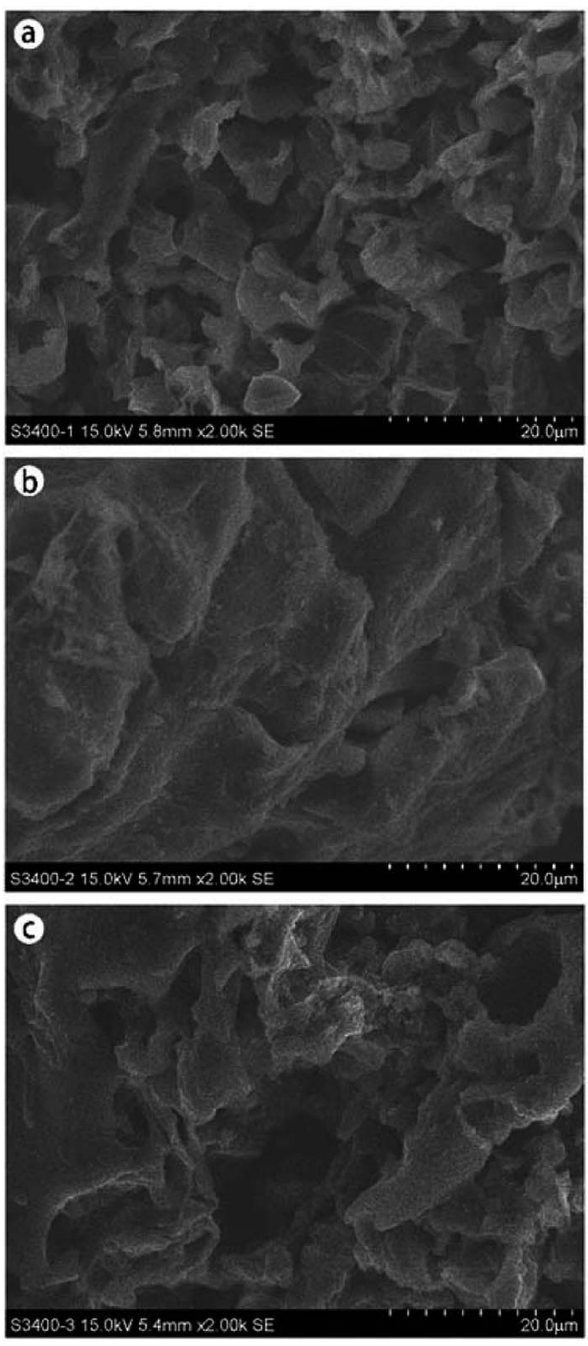

Fig. 3 SEM morphologies of carbonaceous materials (a), the carbon catalysts sulfonated by concentrated sulfuric acid (b) and $\left[\mathrm{HO}_{3}-\right.$ $\mathrm{S}\left(\mathrm{CH}_{2}\right)_{4} \mathrm{mim}_{\mathrm{HSO}} \mathrm{HS}_{4}$ (c).

3.2.4. FTIR analysis results. FTIR spectra of the raw materials (a), carbonaceous materials (b), and the sulfonated carbon catalyst prepared by $\left[\mathrm{HO}_{3} \mathrm{~S}\left(\mathrm{CH}_{2}\right)_{4} \mathrm{mim}\right] \mathrm{HSO}_{4}$ (c) in the wavelength range of $4000-500 \mathrm{~cm}^{-1}$ are shown in Fig. 5 . The peak at $3400 \mathrm{~cm}^{-1}$ was attributed to the hydroxyl group $(-\mathrm{OH})$ stretching and bending vibrations based on the study of Boonamnuayvitaya et $a .^{38}$ Compared to the spectrum of raw materials, no evident peaks were observed in the spectra of carbonaceous materials and the sulfonated carbon catalyst, which suggested that the carbonizing process led to water loss. The band at $1700 \mathrm{~cm}^{-1}$ in the FTIR spectrum of the sulfonated carbon catalyst prepared by $\left[\mathrm{HO}_{3} \mathrm{~S}\left(\mathrm{CH}_{2}\right)_{4} \mathrm{mim}\right] \mathrm{HSO}_{4}$ is attributed to the carbonyl group $(\mathrm{C}=\mathrm{O})$ of carboxyl $(-\mathrm{COOH})$, while the band at $1600 \mathrm{~cm}^{-1}$ can be assigned to the carbon-carbon double bond $(\mathrm{C}=\mathrm{C})$ of the poly-aromatic rings in the carbonaceous materials and sulfonated carbon catalyst. ${ }^{39}$ The peak around $634 \mathrm{~cm}^{-1}$ was attributed to $\mathrm{S}=\mathrm{O}$ stretching vibration, and the vibration bands at $1155 \mathrm{~cm}^{-1}$ and $1032 \mathrm{~cm}^{-1}$ were assigned to symmetrical stretching vibration bands in $\mathrm{O}=\mathrm{S}=\mathrm{O}$ and $\mathrm{SO}^{2-}$ stretching vibrations, which clearly indicated that the prepared sulfonated carbon catalyst surface was functionalized by the use of $\left[\mathrm{HO}_{3} \mathrm{~S}\left(\mathrm{CH}_{2}\right)_{4} \mathrm{mim}\right] \mathrm{HSO}_{4} \cdot{ }^{40-43}$ The significant peak at around $1450 \mathrm{~cm}^{-1}$ illustrated the presence of $\mathrm{CH}_{2}$ bending mode, and the aliphatic areas $\left(\mathrm{CH}_{2}-\mathrm{CH}_{2}\right.$ chains $)$ were sufficiently abundant, as confirmed in the infrared spectrum. ${ }^{\mathbf{4 4}}$ Therefore, the FTIR spectrum clearly suggests that after the sulfonation process using $\left[\mathrm{HO}_{3} \mathrm{~S}\left(\mathrm{CH}_{2}\right)_{4} \mathrm{mim}\right] \mathrm{HSO}_{4},-\mathrm{SO}_{3} \mathrm{H}$ groups have been successfully introduced into the $C$. longepaniculatum leaves-derived catalyst.

3.2.5. TG results. TG and DTG curves of $\left[\mathrm{HO}_{3} \mathrm{~S}\left(\mathrm{CH}_{2}\right)_{4} \mathrm{mim}\right]$ $\mathrm{HSO}_{4}$ (A), carbonaceous samples (B), sulfonated carbon catalysts prepared by $\left[\mathrm{HO}_{3} \mathrm{~S}\left(\mathrm{CH}_{2}\right)_{4} \mathrm{mim}\right] \mathrm{HSO}_{4}(\mathrm{C})$ and concentrated sulfuric acid (D) were plotted as shown in Fig. 6a and (b). For $\left[\mathrm{HO}_{3} \mathrm{~S}\left(\mathrm{CH}_{2}\right)_{4} \mathrm{mim}\right] \mathrm{HSO}_{4}$, it can be observed that the thermal decomposition temperature was much higher than those of carbonaceous samples and sulfonated carbon catalysts as its onset temperature was around $300{ }^{\circ} \mathrm{C}$ and the final temperature was $392{ }^{\circ} \mathrm{C}$. As for the carbonaceous samples (B), the sulfonated carbon catalysts prepared by $\left[\mathrm{HO}_{3} \mathrm{~S}\left(\mathrm{CH}_{2}\right)_{4} \mathrm{mim}\right] \mathrm{HSO}_{4}(\mathrm{C})$ and concentrated sulfuric acid (D), both the sulfonated carbon catalysts showed a similar tendency in weight loss, which were obviously different from that of $\left[\mathrm{HO}_{3} \mathrm{~S}\left(\mathrm{CH}_{2}\right)_{4} \mathrm{mim}\right] \mathrm{HSO}_{4}$. It was seen that the first weight loss below $100{ }^{\circ} \mathrm{C}$ was due to water desorption. ${ }^{45}$ Compared to the carbonized samples (B), sulfonated carbon catalysts prepared by $\left[\mathrm{HO}_{3} \mathrm{~S}\left(\mathrm{CH}_{2}\right)_{4} \mathrm{mim}\right] \mathrm{HSO}_{4}$ (C) and concentrated sulfuric acid (D) presented more apparent decreasing tendencies, which assumes that the prepared sulfonated carbon catalysts possessed hydrophilic properties; a similar phenomenon was also observed in a previous study. ${ }^{46}$ The second weight loss of the sulfonated carbon catalysts prepared by $\left[\mathrm{HO}_{3} \mathrm{~S}\left(\mathrm{CH}_{2}\right)_{4} \mathrm{mim}\right] \mathrm{HSO}_{4}$ and concentrated sulfuric acid is found in the temperature range from $190{ }^{\circ} \mathrm{C}$ to $750{ }^{\circ} \mathrm{C}$, which is likely due to the decomposition of functional groups (e.g., sulfonic, carboxylic, carbonyl, and phenolic and groups) and a small mass of carbon support. ${ }^{3,7}$

3.2.6. EA results. The elemental composition of carbonaceous materials and the sulfonated carbon catalyst prepared by $\left[\mathrm{HO}_{3} \mathrm{~S}\left(\mathrm{CH}_{2}\right)_{4} \mathrm{mim}\right] \mathrm{HSO}_{4}$ was analyzed in Table 1 . It is notable that the sulfur percentage $(3.27 \% \pm 0.06 \%)$ and oxygen percentage $(26.95 \% \pm 0.60 \%)$ of the obtained sulfonated carbon catalyst were observed to be drastically increased after sulfonation treatment with $\left[\mathrm{HO}_{3} \mathrm{~S}\left(\mathrm{CH}_{2}\right)_{4} \mathrm{mim}\right] \mathrm{HSO}_{4}$ as compared to the carbonaceous materials $(0.27 \% \pm 0.01 \%$ for sulfur and $21.61 \% \pm 0.54 \%$ for oxygen), which confirmed the presence of large amounts of sulfur- and oxygen-containing groups compounds in the sulfonated carbon catalyst prepared by $\left[\mathrm{HO}_{3} \mathrm{~S}\left(\mathrm{CH}_{2}\right)_{4} \mathrm{mim}\right] \mathrm{HSO}_{4}$. Hence, it can be concluded that the sulfonic groups were successfully functionalized via sulfonation on the surface of $C$. longepaniculatum leaves-derived carbonaceous materials, which also corresponds well with the FTIR analysis results. The $\mathrm{C} / \mathrm{O}$ ratio was found to be 2.47 for the obtained sulfonated carbon catalyst. In a previous study, which was performed by Zaman et al. ${ }^{\mathbf{4 4}}$ it was found that, based on the EA analysis, the sulfur content was $4.98 \pm 0.73 \%$ with a $\mathrm{C} / \mathrm{O}$ ratio of 4.43 . This is very close to the determined values in the present study. It is understandable that some differences 

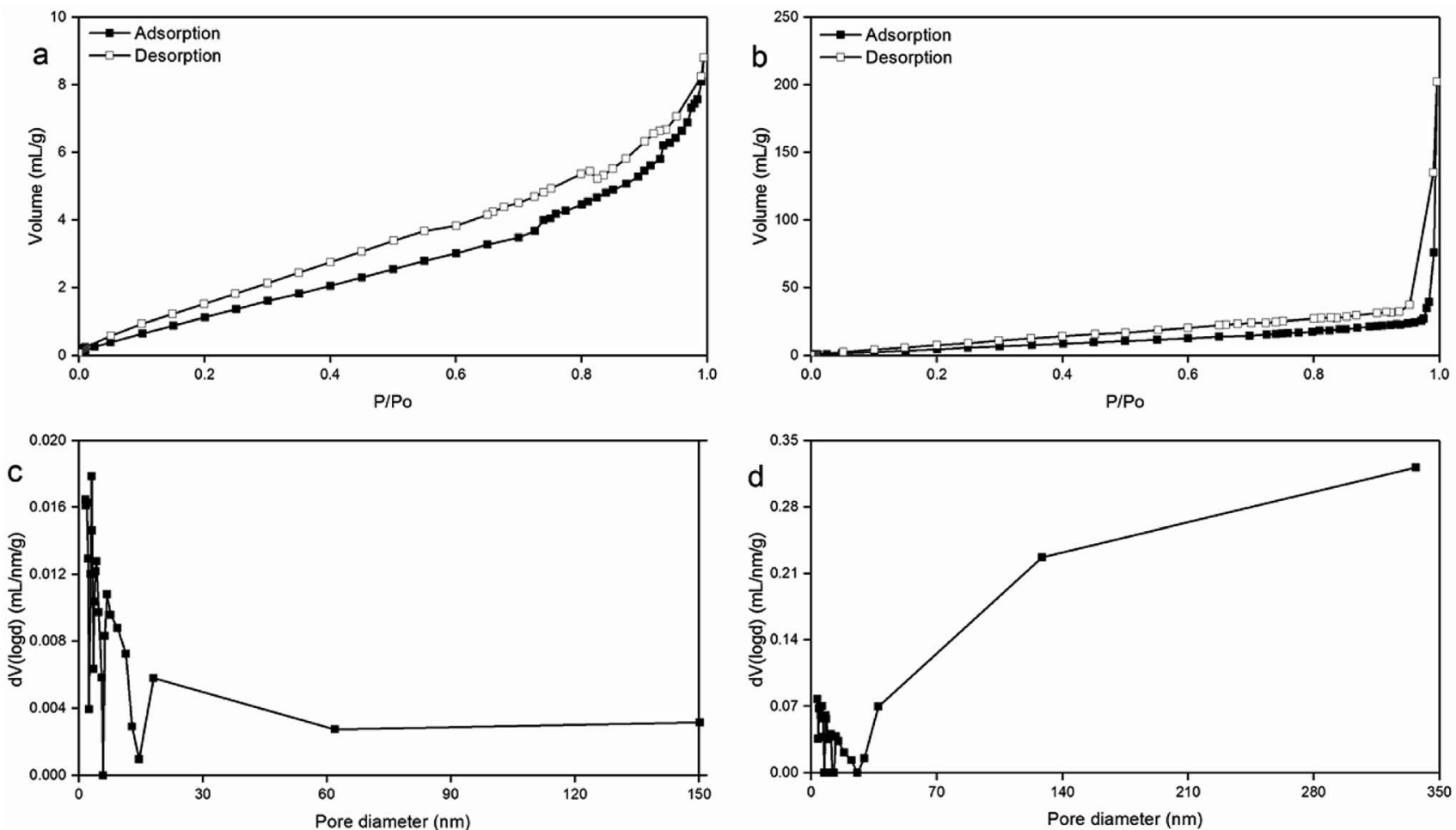

Fig. 4 Nitrogen adsorption/desorption isotherms of the sulfonated carbon catalysts prepared by concentrated sulfuric acid (a) and [HO ${ }_{3}-$ $\left.\mathrm{S}_{\left(\mathrm{CH}_{2}\right.}\right)_{4}$ mim] $\mathrm{HSO}_{4}$ (b) and the pore size distribution for the sulfonated carbon catalysts prepared by concentrated sulfuric acid (c) and [ $\mathrm{HO}_{3}-$ $\left.\mathrm{S}\left(\mathrm{CH}_{2}\right)_{4} \mathrm{mim}\right] \mathrm{HSO}_{4}$ (d).

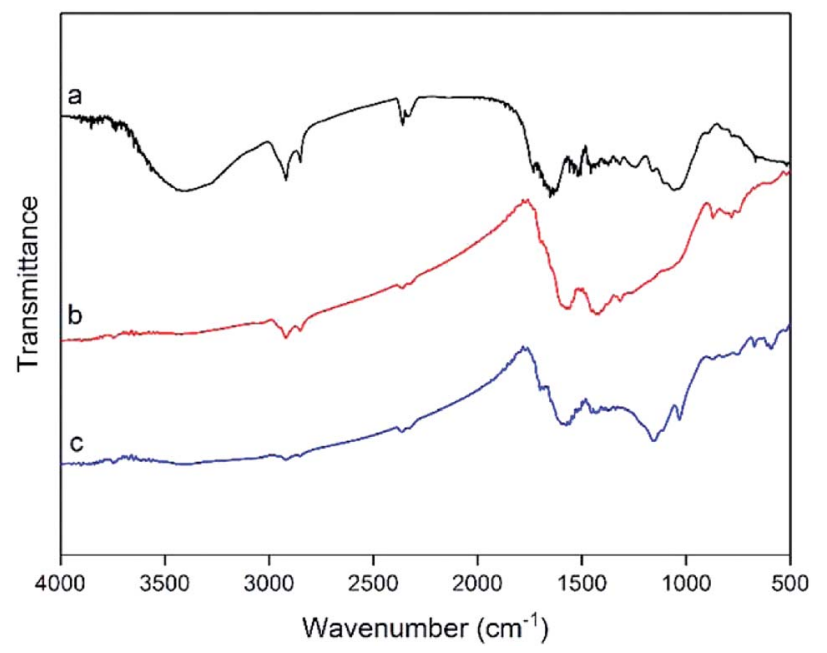

Fig. 5 FTIR spectra of raw materials after recovery of essential oil from the leaves of Cinnamomum longepaniculatum (a), carbonized materials (b), and sulfonated carbon catalyst prepared by $\left[\mathrm{HO}_{3} \mathrm{~S}\left(\mathrm{CH}_{2}\right)_{4} \mathrm{mim}\right]$ $\mathrm{HSO}_{4}$ (c).

existed in the different raw materials used as well as the reaction parameters (such as temperature and time) applied between the two researches.

3.2.7. XPS results. Fig. 7 shows the XPS spectra of the sulfonated carbon catalyst prepared by $\left[\mathrm{HO}_{3} \mathrm{~S}\left(\mathrm{CH}_{2}\right)_{4} \mathrm{mim}\right]$
$\mathrm{HSO}_{4}$. Three characteristic peaks that can be assigned to oxygen, sulfur, and carbon in the obtained sulfonated carbon catalyst were observed with binding energies at $532 \mathrm{eV}$, $284.5 \mathrm{eV}$ and $168 \mathrm{eV}$, respectively. Fig. 7b shows the high resolution spectra of $\mathrm{O} 1 \mathrm{~s}$. The two peaks with binding energies at $533 \mathrm{eV}$ and $531.6 \mathrm{eV}$ belong to $\mathrm{C}-\mathrm{OH}$ and $\mathrm{C}=\mathrm{O}$, respectively. Fig. 7c shows the high resolution spectra of $\mathrm{S} 2 \mathrm{p}$. The two sulfur peaks with binding energies at 164.0 and $165.2 \mathrm{eV}$ can be ascribed to the $\mathrm{S} 2 \mathrm{p}_{3 / 2}$ and $\mathrm{S} 2 \mathrm{p}_{1 / 2}$ of thiophenic sulphur (-C-S-C-), respectively. ${ }^{47}$ Fig. $7 \mathrm{~d}$ displays the high resolution spectra of $\mathrm{C} 1 \mathrm{~s}$. The main characteristic peak at $284.5 \mathrm{eV}$ can be assigned to carbon atoms with $\mathrm{sp}^{2}$ hybridization. Based on the literature ${ }^{48}$ the peaks at $288.6 \mathrm{eV}$ and $284.6 \mathrm{eV}$ belong to $\mathrm{C}-\mathrm{C}$ and $\mathrm{C}-\mathrm{O}$, respectively.

3.2.8. Total acidic content of the sulfonated carbon catalyst prepared by $\left[\mathrm{HO}_{3} \mathrm{~S}\left(\mathrm{CH}_{2}\right)_{4} \mathrm{mim}\right] \mathrm{HSO}_{4}$. As is commonly known, acidic capacity is a crucial factor for the acidic catalysis process. The total acidic contents were determined at different sulfonation temperatures as presented in Fig. 8 based on the results of the acid-base titration experiments. The total acidic contents of the sulfonated carbon catalyst prepared by $\left[\mathrm{HO}_{3}-\right.$ $\left.\mathrm{S}\left(\mathrm{CH}_{2}\right)_{4} \mathrm{mim}\right] \mathrm{HSO}_{4}$ apparently varied with different sulfonation temperatures. The maximum total acidic capacity $(1.18 \pm$ $0.02 \mathrm{mM} \mathrm{g}^{-1}$ ) was obtained at $200{ }^{\circ} \mathrm{C}$ sulfonation treatment for $2 \mathrm{~h}$. It suggests that the increase in the sulfonation temperature to $200{ }^{\circ} \mathrm{C}$ resulted in the maximum acidic capacity, and a further increase of the sulfonation temperature did not 

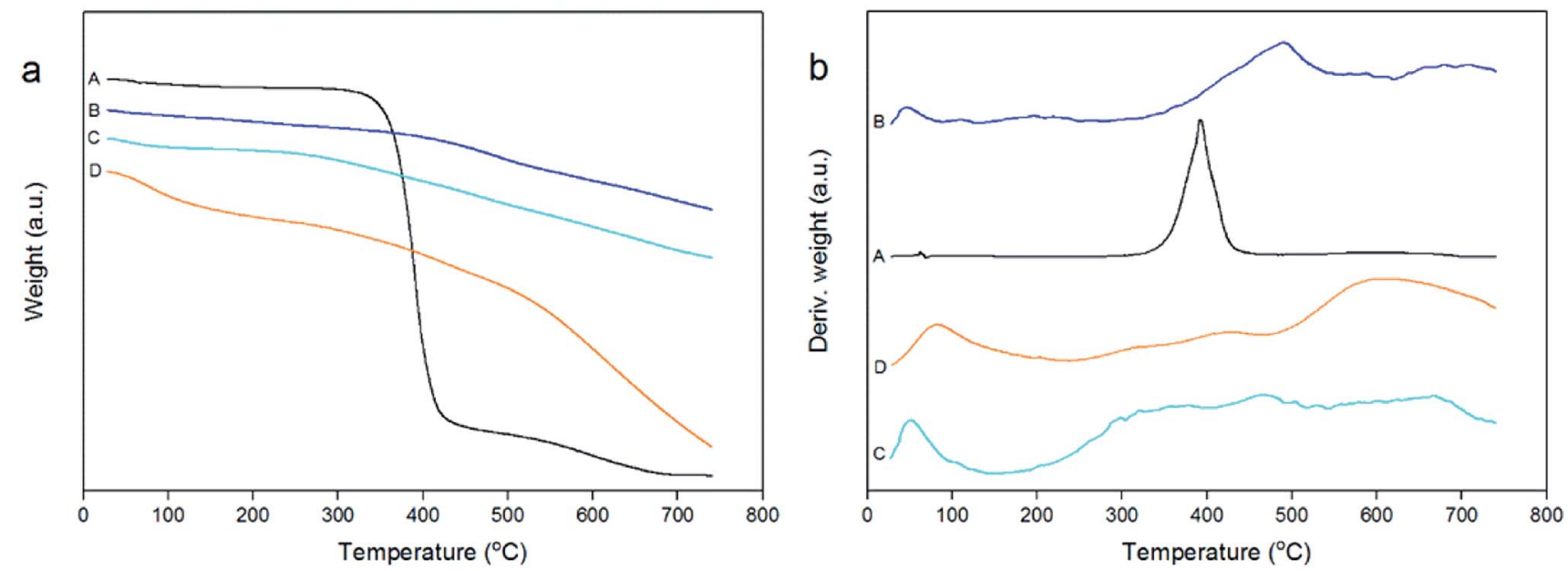

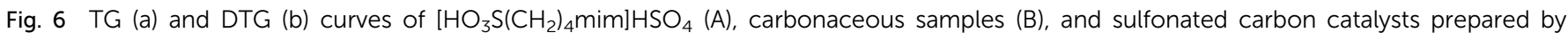
$\left.\left[\mathrm{HO}_{3} \mathrm{~S}_{(\mathrm{CH}}\right)_{4} \mathrm{mim}\right] \mathrm{HSO}_{4}(\mathrm{C})$ and concentrated sulfuric acid (D).

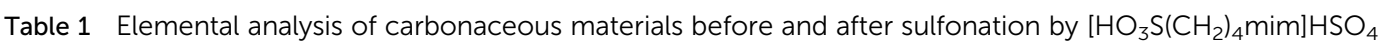

\begin{tabular}{|c|c|c|c|c|}
\hline Samples & $\mathrm{C} \%$ & $\mathrm{H} \%$ & $\mathrm{O} \%$ & $\mathrm{~S} \%$ \\
\hline Carbonaceous materials & $74.52 \pm 2.32$ & $3.60 \pm 0.12$ & $21.61 \pm 0.54$ & $0.27 \pm 0.01$ \\
\hline Sulfonated carbon catalyst prepared by $\left[\mathrm{HO}_{3} \mathrm{~S}\left(\mathrm{CH}_{2}\right)_{4} \mathrm{mim}\right] \mathrm{HSO}_{4}$ & $66.46 \pm 1.86$ & $3.32 \pm 0.08$ & $26.95 \pm 0.60$ & $3.27 \pm 0.06$ \\
\hline
\end{tabular}
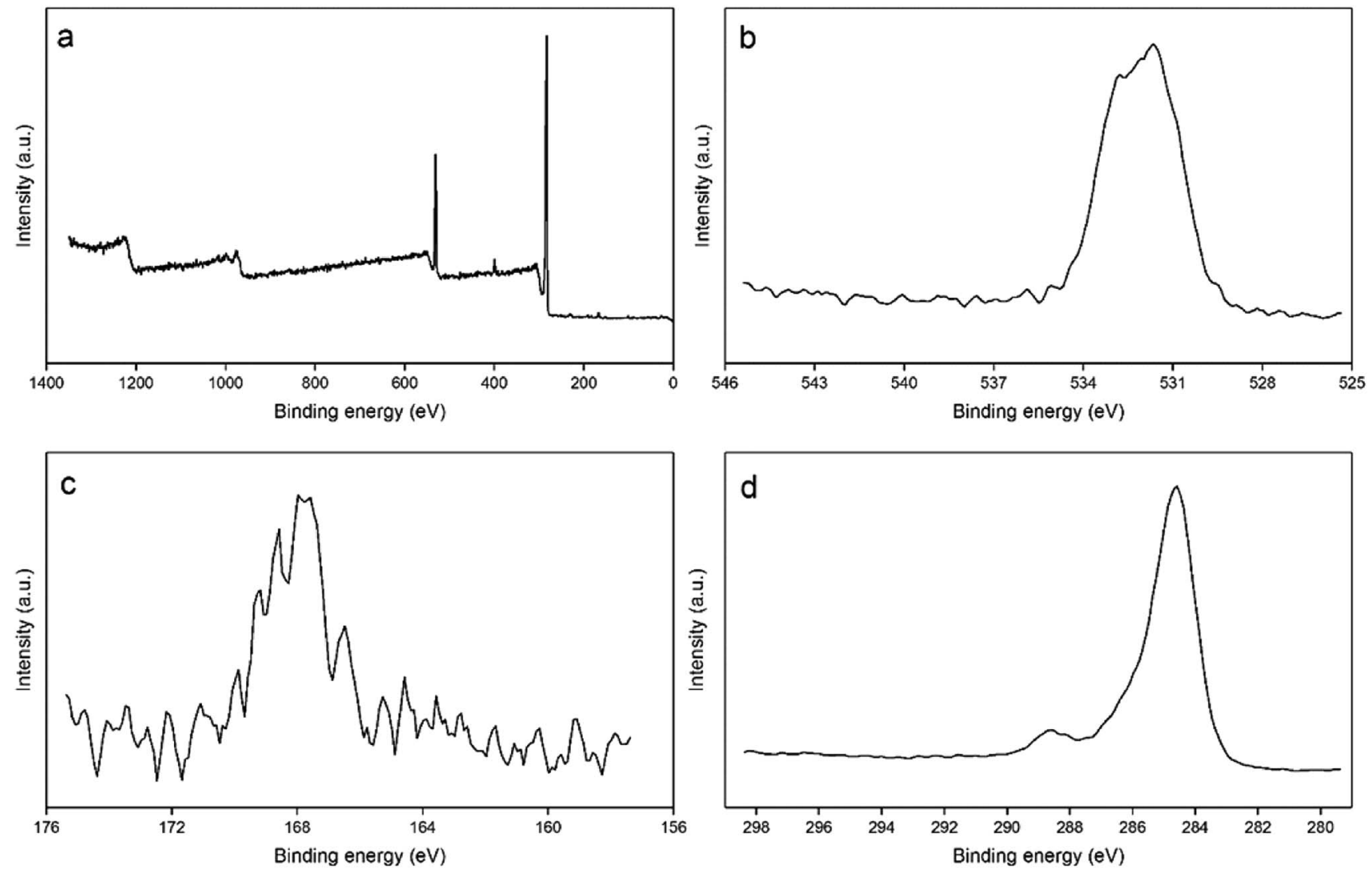

Fig. 7 XPS spectra of the sulfonated carbon catalysts prepared by $\left[\mathrm{HO}_{3} \mathrm{~S}\left(\mathrm{CH}_{2}\right)_{4}\right.$ mim] $\mathrm{HSO}_{4}$ (a). High-resolution of $\mathrm{O} 1 \mathrm{~s}$ (b), $\mathrm{S} 2 \mathrm{p} \mathrm{(c),} \mathrm{and} \mathrm{C} 1 \mathrm{~s}$ (d). 


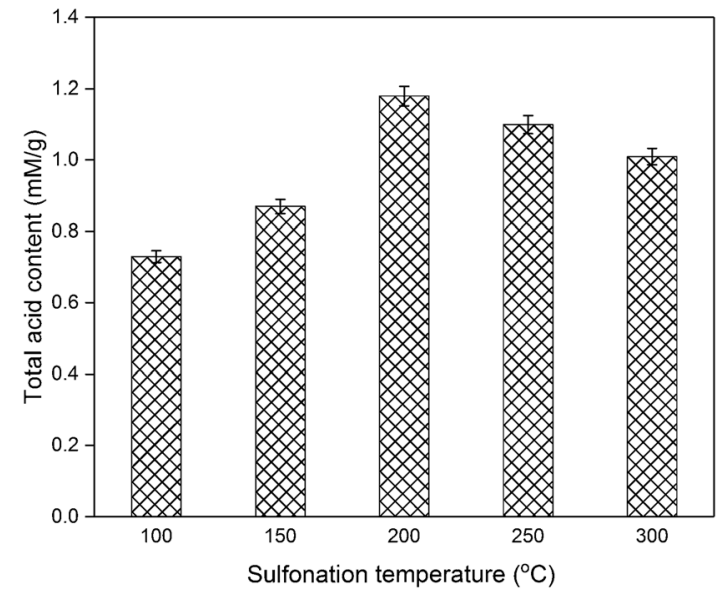

Fig. 8 Total acidic content of the sulfonated carbon catalysts prepared by $\left[\mathrm{HO}_{3} \mathrm{~S}\left(\mathrm{CH}_{2}\right)_{4}\right.$ mim] $\mathrm{HSO}_{4}$ versus sulfonation temperature.

improve the total acid contents of the obtained sulfonated carbon catalyst. This phenomenon was due to the fact that an increase in the sulfonation temperature could trigger more $-\mathrm{SO}_{3} \mathrm{H}$ group to attach with the carbonaceous materials layer, thus resulting in a relatively higher acidic ability. Further increases in the temperature did not increase the acidity of the prepared sulfonated carbon catalyst, which was likely due to the attainment of the adsorption-desorption equilibrium of $-\mathrm{SO}_{3} \mathrm{H}$ groups on the carbonaceous material surface.

3.2.9. Reusability of the sulfonated carbon catalyst prepared by $\left[\mathrm{HO}_{3} \mathrm{~S}\left(\mathrm{CH}_{2}\right)_{4} \mathrm{mim}\right] \mathrm{HSO}_{4}$. The reusability study of the sulfonated carbon catalyst prepared by $\left[\mathrm{HO}_{3} \mathrm{~S}\left(\mathrm{CH}_{2}\right)_{4} \mathrm{mim}\right]$ $\mathrm{HSO}_{4}$ was performed up to five consecutive catalytic trials for the preparation of ellagic acid and gallic acid (Fig. 9). The yields of the two target compounds were found to be slightly decreased, but the catalytic ability still remained around $80 \%$ compared to that of the freshly sulfonated carbon catalyst after each catalytic trial. This is probably due to the adsorption of reaction complexes on the surface of the sulfonated carbon catalyst prepared by $\left[\mathrm{HO}_{3} \mathrm{~S}\left(\mathrm{CH}_{2}\right)_{4} \mathrm{mim}\right] \mathrm{HSO}_{4}$, therefore resulting in the poisoning of the acid sites or the loss of functional sites from the obtained sulfonated carbon catalyst surface over the period of the catalytic trials. A similar tendency of reduction in

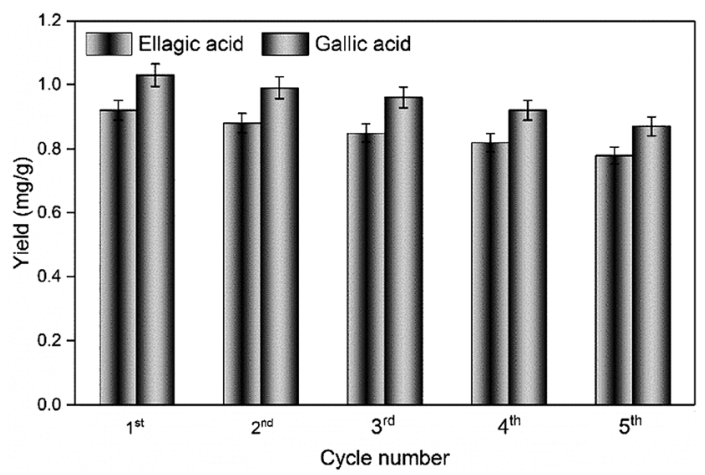

Fig. 9 The reusability study of the sulfonated carbon catalyst prepared by $\left[\mathrm{HO}_{3} \mathrm{~S}\left(\mathrm{CH}_{2}\right)_{4} \mathrm{mim}\right] \mathrm{HSO}_{4}$. the catalytic ability was observed in the case of similar sulfonated carbon catalysts. ${ }^{37}$

\section{Conclusions}

An attempt was carried out towards the utilization of the residue obtained after the recovery of essential oil from the C. longepaniculatum leaves for the preparation of sulfonated carbon catalyst by using $\left[\mathrm{HO}_{3} \mathrm{~S}\left(\mathrm{CH}_{2}\right)_{4} \mathrm{mim}\right] \mathrm{HSO}_{4}$. The sulfonation conditions for the preparation of the C. longepaniculatum sulfonated carbon catalyst were as follows: $0.09 \mathrm{M}$ of $\left[\mathrm{HO}_{3}-\right.$ $\left.\mathrm{S}\left(\mathrm{CH}_{2}\right)_{4} \mathrm{mim}\right] \mathrm{HSO}_{4}, 200{ }^{\circ} \mathrm{C}$ as the sulfonation temperature, and $2 \mathrm{~h}$ as the sulfonation time. XRD results revealed that the prepared sulfonated carbon catalyst has an amorphous carbon structure. The $-\mathrm{SO}_{3} \mathrm{H}$ functionalization on the obtained sulfonated carbon catalyst surface was characterized by XRD, SEM, $\mathrm{N}_{2}$ adsorption-desorption isotherms, FTIR spectroscopy, XPS and EA analysis. TG analysis indicated that the obtained sulfonated carbon catalyst has a high thermal stability. The obtained sulfonated carbon catalyst was used in the catalysis of hydrolysable tannins contained in Eucalyptus globulus leaves to prepare ellagic acid and gallic acid. The results revealed that the obtained sulfonated carbon catalyst from the residue obtained after the recovery of essential oil from the leaves of Cinnamomum longepaniculatum possesses high catalytic activity and high reuse capacity.

\section{Conflicts of interest}

The authors declare no conflict of interest.

\section{Acknowledgements}

The authors thank the Fundamental Research Fund by the National Natural Science Foundation of China (31860189) for financial support.

\section{References}

1 P. Gallezot, Chem. Soc. Rev., 2012, 41, 1538.

2 L. R. Lynd, P. J. Weimer, W. H. van Zyl and I. S. Pretorius, Microbiol. Mol. Biol. Rev., 2002, 66, 506.

3 M. Tao, H. Guan, X. Wang, Y. Liu and R. F. Louh, Fuel Process. Technol., 2015, 138, 355.

4 S. Chen, S. Tang, Y. Sun, G. Wang, H. Chen, X. Yu, Y. Su and G. Chen, Materials, 2018, 11, 1407.

5 T. Teng, T. C. Hsiao and C. C. Chung, Materials, 2018, 11, 1315.

6 D. Mun, A. T. H. Vo, B. Kim, Y. G. Shul and J. K. Cho, Catal. Commun., 2017, 96, 32.

7 D. R. Lathiya, D. V. Bhatt and K. C. Maheria, Bioresource Technology Reports, 2018, 2, 69.

8 C. Tao, Afr. J. Pharm. Pharmacol., 2013, 7, 1148.

9 Z. Luo, W. Li, Q. Wei and T. Luo, J. Sichuan Norm. Univ., 2001, 24, 317 . 
10 Y. Amakura, M. Yoshimura, N. Sugimoto, T. Yamazaki and T. Yoshida, Biosci., Biotechnol., Biochem., 2009, 73, 10601065.

11 B. Song, Shaanxi Huagong, 1988, 3, 14.

12 P. Fyhrquist, I. Laakso, S. Garcia Marco, R. Julkunen-Tiitto and R. S. Hiltunen, S. Afr. J. Bot., 2014, 90, 1.

13 M. Albrecht, W. Jiang, J. Kumi-Diaka, E. P. Lansky, L. M. Commersall, A. Patel, R. Mansel, I. Neeman, A. A. Geldof and M. J. Campbell, J. Med. Food, 2004, 7, 274.

14 Z. Liu, Z. Chen, F. Han, X. Kang, H. Gu and L. Yang, Ind. Crops Prod., 2016, 81, 152.

15 I. Mueller-Harvey, Anim. Feed Sci. Technol., 2001, 91, 3.

16 S. H. Häkkinen, S. O. Kärenlampi, H. M. Mykkänen, I. M. Heinonen and A. R. Törrönen, Eur. Food Res. Technol., 2000, 212, 75-80.

17 J. M. Cruz, H. Domínguez and J. C. Parajó, Food Chem., 2005, 90, 503.

18 S. Gamez, J. J. Gonzalez-Cabriales, J. A. Ramirez, G. Garrote and M. Vazquez, J. Food Eng., 2006, 74, 78.

19 K. Weerasai, V. Champreda, C. Sakdaronnarong, A. Shotipruk and N. Laosiripojana, Food Bioprod. Process., 2018, 110, 136.

20 P. Lenihan, A. Orozco, E. O' Neill, M. N. M. Ahmad, D. W. Rooney and G. M. Walker, Chem. Eng. J., 2010, 156, 395.

21 K. Karimi, S. Kheradmandinia and M. J. Taherzadeh, Biomass Bioenergy, 2006, 30, 247.

22 M. J. Climent, A. Corma and S. Iborra, Green Chem., 2011, 13, 520.

23 Y. Jiang, X. Li, X. Wang, L. Meng, H. Wang, L. Wang, X. Wang and X. Mu, Green Chem., 2012, 14, 2162.

24 V. L. Budarin, J. H. Clark, R. Luque and D. J. Macquarrie, Chem. Commun., 2007, 6, 634.

25 S. Dora, T. Bhaskar, R. Singh, D. V. Naik and D. K. Adhikari, Bioresour. Technol., 2012, 120, 318.

26 B. L. A. Prabhavathi Devi, K. N. Gangadhar, P. S. Sai Prasad, B. Jagannadh and R. B. N. Prasad, ChemSusChem, 2009, 2, 617.

27 Y. Wang, F. Delbecq, W. Kwapinski and C. Len, Mol. Catal., 2017, 438, 167.
28 P. Ergenekon, E. Gürbulak and B. Keskinler, Chem. Eng. Process., 2011, 50, 16.

29 A. C. Cole, J. L. Jensen, I. Ntai, K. L. T. Tran, K. J. Weaver, D. C. Forbes and J. H. Davis Jr., J. Am. Chem. Soc., 2002, 124, 5962.

30 A. Pourjavadi, S. H. Hosseini and R. Soleyman, J. Mol. Catal. A: Chem., 2012, 365, 55.

31 Y. Shin, M. S. Shon, G. N. Kim and S. C. Lee, Food Sci. Biotechnol., 2014, 23, 1689.

32 K. Ngaosuwan, J. G. Goodwin Jr. and P. Prasertdham, Renewable Energy, 2016, 86, 262.

33 Q. Xu, Y. Xia, D. Yin, C. Fan and Z. Xu, New Carbon Mater., 2011, 26, 103.

34 R. Liu, X. Wang, X. Zhao and P. Feng, Carbon, 2008, 46, 1664. 35 J. R. Kastner, J. Miller, D. P. Geller, J. Locklin, L. H. Keith and T. Johnson, Catal. Today, 2012, 190, 122.

36 S. Niu, Y. Ning, C. Lu, K. Han, H. Yu and Y. Zhou, Energy Convers. Manage., 2018, 163, 59.

37 B. Manoj and A. G. Kunjomana, Int. J. Electrochem. Sci., 2012, 7, 3127.

38 V. Boonamnuayvitaya, C. Chaiya and W. Tanthapanichakoon, J. Chem. Eng. Jpn., 2004, 37, 1504.

39 W. W. Mar and E. Somsook, Procedia Eng., 2012, 32, 212.

40 S. Suganuma, K. Nakajima, M. Kitano, H. Kato, A. Tamura, H. Kondo, S. Yanagawa, S. Hayashi and M. Hara, Microporous Mesoporous Mater., 2011, 143, 443.

41 Z. Jia, Z. Li, S. Li, Y. Li and R. Zhu, J. Mol. Liq., 2016, 220, 56. 42 S. Imaizumi, H. Matsumoto, M. Ashizawa, M. Minagawa and

A. Tanioka, RSC Adv., 2012, 2, 3109.

43 K. Nakajima and M. Hara, ACS Catal., 2012, 2, 1296.

44 A. C. Zaman, J. Mol. Liq., 2018, 249, 892.

45 I. Ogino, Y. Suzuki and S. R. Mukai, Catal. Today, 2018, 314, 62.

46 C. Zhang, Z. Fu, Y. Liu, B. Dai, Y. Zou, X. Gong, Y. Wang, X. Deng, H. Wu, Q. Xu, K. R. Stevena and D. Yin, Ind. Eng. Chem. Res., 2012, 14, 1928.

47 J. Li, Y. Wang, B. Lu, Y. Wang, T. Deng and X. Hou, Appl. Catal., A, 2018, 566, 140.

48 J. Zhou, H. Li, G. Lin and H. Zhang, Acta Phys.-Chim. Sin., 2010, 26, 3080. 